\title{
Surface Localization of Sialic Acid on Actinomyces viscosus
}

\author{
By ALMA H. JONES, ${ }^{1,2 *}$ CHI-CHANG LEE, ${ }^{1} \dagger$ BERNARD J. MONCLA, ${ }^{1,2}$ \\ MURRAY R. ROBINOVITCH ${ }^{1,2}$ AND DALE C. BIRDSELL ${ }^{1} \ddagger$ \\ Departments of Oral Biology ${ }^{1}$ and Periodontics ${ }^{2}$, University of Washington, Seattle, \\ WA 98195, USA
}

(Received 28 April 1986; revised 24 June 1986)

\begin{abstract}
This study reports the presence of sialic acid in Actinomyces viscosus strains T14V and T14AV. Mild acid hydrolysis of whole organisms released a compound which reacted positively in the periodate-thiobarbituric acid, direct Ehrlich's and resorcinol assays, and which cochromatographed on paper with authentic $N$-acetylneuraminic acid. Strain T14V contained $10-$ fold greater concentrations of sialic acid than did strain T14AV. Sialic acid content was dependent upon the stage of growth of the culture, reaching a maximum in early stationary phase. Epifluorescence microscopy of fluorescein isothiocyanate (FITC)-conjugated Limulus polyphemus agglutinin (LPA), a lectin specific for sialic acid, revealed a uniform distribution of bound lectin on the surfaces of strains T14V and T14AV. Additional evidence for surface localization was obtained by demonstration of whole-cell agglutination of both strains with LPA. All LPA interactions with $A$. viscosus were inhibited by the presence of $0.1 \mathrm{M}-\mathrm{N}$ acetylneuraminic acid. Neuraminidases from Clostridium perfringens, Arthrobacter ureafaciens and Vibrio cholerae did not release detectable amounts of sialic acid, but the extracellular enzyme from $A$. viscosus cleaved amounts equivalent to those obtained by acid hydrolysis. Other laboratory strains (W1053, M100, W859, 5-5S, RC45, ATCC 19246, and 'binder') as well as recent clinical isolates of $A$. viscosus were agglutinated by LPA and released sialic acid upon mild acid hydrolysis. Surface-available sialic acid has been implicated in the inhibition of alternative complement pathway activation and subsequent opsonophagocytosis. Thus the occurrence of surface sialic acid in $A$. viscosus may represent a mechanism of pathogenesis for this oral bacterium.
\end{abstract}

\section{INTRODUCTION}

Sialic acids are ubiquitous among vertebrates, do not occur in plants, and are of limited distribution among bacteria. These nine-carbon amino sugar acids are named as derivatives of neuraminic acid; both the generic and trivial names reflect sources rich in this carbohydrate, namely saliva and brain gangliosides. In mammals, sialic acids are constituents of membrane glycoproteins which are important determinants in many cell-cell interactions and function in the specificity of macromolecular binding to cell surface receptors in many systems (Schauer, 1982). Strains of Escherichia coli (Barry, 1959), Neisseria meningitidis (Apicella \& Robinson, 1970; Liu et al., 1971) and group B Streptococcus (Baker \& Kasper, 1976a) produce capsular polysaccharides which contain terminal sialic acid residues. E. coli and $N$. meningitidis produce homopolymers or simple alternating copolymers, whereas the group B streptococci synthesize

\footnotetext{
† Present address: Department of Microbiology, SC-42, University of Washington, Seattle, WA 98195, USA. $\ddagger$ Present address: Box 365, 10636 Main Street, Bellevue, WA 98004, USA.

Abbreviations: NeuAc, $N$-acetylneuraminic acid; NeuLac, $N$-acetylneuraminlactose; BSM, bovine submaxillary mucin; LPA, Limulus polyphemus agglutinin; LFA, Limax flavus agglutinin; WGA, wheat germ agglutinin; FITC, fluorescein isothiocyanate; PTA, periodic acid-thiobarbituric acid; KDO, 3-deoxyoctulosonic acid.
} 
more complex carbohydrate structures bearing terminal sialic acid residues. Also, sialic acid has been demonstrated in Salmonella species (Barry et al., 1962; Kedzierska, 1978), Citrohacter freundii (Barry et al., 1962) and Corynebacterium parvum (Dawes et al., 1974).

The common denominator among these micro-organisms is that all represent members of the normal human flora which can infect as opportunistic pathogens. In particular, E. coli, N. meningitidis and group B Streptococcus strains encapsulated by sialic-acid-containing polymers are the most common causative agents of meningitis among infants and septicaemia in immunocompromised patients (Mulder \& Zanen, 1984; Pangburn \& Muller-Eberhard, 1978; Robbins et al., 1974). Polysaccharide material on these organisms may be a significant virulence factor, since it correlates with a decrease in opsonophagocytosis and enhanced invasiveness (Bortolussi et al., 1979; Schauer, 1982; Varki \& Diaz, 1984).

Actinomyces viscosus is an important member of the oral flora in several respects. The organism is numerically common in established supragingival (Syed \& Loesche, 1978) and subgingival plaque (Newman \& Sims, 1979), is associated with the development of gingivitis (Loesche \& Syed, 1978; Syed \& Loesche, 1978), causes periodontal disease in animal models (Brecher et al., 1978; Jordan et al., 1972) and occasionally behaves as an opportunistic pathogen in lung infections.

In this study, A. viscosus strains T14V and T 14AV were utilized to investigate the occurrence of sialic acid on this oral bacterium. Strain T14AV (avirulent) is a spontaneous laboratory variant of strain $\mathrm{T} 14 \mathrm{~V}$ (virulent) which produces large amounts of an extracellular polysaccharide material, is unable to colonize the teeth of gnotobiotic rats (Brecher et al., 1978), and shows markedly decreased adherence to saliva-treated hydroxyapatite (Moncla et al., 1985). The polysaccharide produced by T14AV probably accounts for its limited ability to colonize the oral cavity. Several experimental techniques were employed to demonstrate the presence of sialic acid on the surface of both strains T14V and T14AV. This observation was extended to other isolates of $A$. viscosus, suggesting that surface sialic acid is a general trait of serotype 2 strains of this species, and by analogy to other systems, may be an important virulence factor. A preliminary report of this study has appeared (Jones et al., 1983).

\section{METHODS}

Materials. Tryptic soy broth and yeast extract were from Difco. $N$-Acetylneuraminic acid (NeuAc), $N$ acetylneuraminlactose (NeuLac), bovine submaxillary mucin (BSM), Clostridium perfringens neuraminidase, and lectin from Limulus polyphemus were obtained from Sigma. Neuraminidase from Arthrobacter ureafaciens and Vibrio cholerae were purchased from Calbiochem-Behring. Affinity-purified lectins from Limulus polyphemus (LPA), Limax flavus (LFA) and Triticum vulgaris (wheat germ agglutinin, WGA), as well as fluorescein isothiocyanate (FITC)-conjugated LPA and FITC-conjugated rabbit antiserum to LPA, were obtained from E-Y Laboratories, San Mateo, Calif., USA.

Source of culures. Laboratory strains T14V and T14AV of A. viscosus and clinical isolates UF620, UF636 and UF810 were from our stock culture collection. Laboratory strains W1053 and W859 of $A$. viscusus were obtained from Sandra Bragg, CDC, Atlanta, Ga., USA. A. viscosus strains M100, 5-5S and 'binder' were from Howard Bladen, NIDR, Bethesda, Md., USA, and RC45 was from Arthur D. Eisenberg, Eastman Dental Center, Rochester, NY, USA. Strain ATCC 19246 of $A$. viscosus was provided by one of us (B. J. M.). Clinical isolates GB3 and GB4 were from George Bowden, University of Manitoba, Winnipeg, Canada. Group B, type III Streptococcus was obtained from Steve Mattingly, University of Texas Health Science Center, San Antonio, Tx., USA.

Media and growth conditions. Bacteria were grown in tryptic soy broth supplemented with $0.5 \%(\mathrm{w} / \mathrm{v})$ glucose and $0.1 \%(\mathrm{w} / \mathrm{v})$ yeast extract, and buffered with $15 \mathrm{~mm}$-sodium bicarbonate, $\mathrm{pH} 7.4$ (TSBS). Cultures were inoculated $(0.1 \%, \mathrm{v} / \mathrm{v})$ from stock suspensions of bacteria stored at $-70{ }^{\circ} \mathrm{C}$ in $20 \%(\mathrm{v} / \mathrm{v})$ glycerol, sparged for $30 \mathrm{~s}$ with $\mathrm{N}_{2} / \mathrm{CO}_{2}(95: 5, \mathrm{v} / \mathrm{v})$, and incubated at $37^{\circ} \mathrm{C}$ on a gyratory shaker at 250 r.p.m. Growth was monitored turbidimetrically with a Klett-Summerson colorimeter (no. 66 filter). Cultures were harvested by centrifugation at $10000 \mathrm{~g}$ and washed twice with $0.01 \mathrm{~m}$-sodium phosphate $/ 0.15 \mathrm{M}-\mathrm{NaCl}$ (PBS). The $\mathrm{pH}$ of the washing medium was adjusted to the final culture $\mathrm{pH}$, and ranged from $\mathrm{pH} 6.7$ for early exponential phase cultures to $\mathrm{pH} 4.9$ for stationary phase cultures.

Hydrolysis conditions. A wide range of hydrolysis conditions based upon published methods were examined (Schauer, 1982). The concentrations of acids employed were $0.01-1 \cdot 0 \mathrm{M}-\mathrm{H}_{2} \mathrm{SO}_{4}, 0.005-0.1 \mathrm{M}-\mathrm{HCl}$ and $0.175-0.7 \mathrm{M}$ acetic acid for times from $15 \mathrm{~min}$ to $4 \mathrm{~h}$ at $0,25,37$ and $85^{\circ} \mathrm{C}$. Also, cells were extracted at $85^{\circ} \mathrm{C}$ in distilled water. Hydrolyses were performed with weighed pellets of washed bacterial cells suspended in 10 vols distilled water per 
unit of wet weight. A sample was taken at this point for dry weight measurement as needed. The cell suspension was adjusted to the desired acid concentration, hydrolysed, cooled and centrifuged for $10 \mathrm{~min}$ at $10000 \mathrm{~g}$. The supernatant fluids were stored at $-20^{\circ} \mathrm{C}$ until assayed. The positive control group B type III Streptococcus was hydrolysed in $0.35 \mathrm{M}$-acetic acid at $85^{\circ} \mathrm{C}$ for $25 \mathrm{~min}$. Uninoculated medium was hydrolysed by addition of acetic acid to $0.35 \mathrm{M}$ and incubation for $45 \mathrm{~min}$ at 37 and $85^{\circ} \mathrm{C}$.

Preparation of neuraminidase from $A$. viscosus and neuraminidase assays. Crude soluble neuraminidase was prepared from $A$. viscosus T14V by incubation of bacterial cells in PBS overnight at $37^{\circ} \mathrm{C}$ (Costello et al., 1979). Strain T14V was harvested at late exponential phase $(20 \mathrm{~h})$, washed three times in PBS containing $0 \cdot 2 \%$ sodium azide, and suspended in buffer to the original culture volume. After overnight extraction at $37^{\circ} \mathrm{C}$ in a shaking incubator at 250 r.p.m., the supernatant fluid was vacuum dialysed against $5 \cdot 51$ PBS at $4{ }^{\circ} \mathrm{C}$ overnight to a final protein concentration of $150 \mu \mathrm{g} \mathrm{ml}^{-1}$ in a MicroProDiCon (BioMolecular Dynamics, Beaverton, Ore., USA) with a molecular mass cut-off of $10 \mathrm{kDa}$. The dialysed and concentrated buffer extract was assayed for both protease and neuraminidase activities. Protease activity was measured as TCA-soluble products of casein hydrolysate as determined by the Lowry method, and was absent from the enzyme preparation. Neuraminidase activity of the preparation was assayed in PBS at $37^{\circ} \mathrm{C}$ (Costello et al., 1979) and compared with C. perfringens neuraminidase under the same conditions using NeuLac and BSM as substrates. The assay consisted of $15 \mu \mathrm{g}$ protein of the crude A. viscosus enzyme preparation or 0.1 units of the commercial enzyme in $0.6 \mathrm{ml}$ total reaction volume containing $100 \mu \mathrm{g}$ NeuLac or BSM. Both enzymes released sialic acid from the control substrates in $1 \mathrm{~h}$ incubations. Specific activities (expressed in $\mathrm{nmol} \mu \mathrm{g}^{-1} \mathrm{~h}^{-1}$ ) for the $A$. viscosus enzyme were 1 and 4 for BSM and NeuLac, respectively, and 16 and 45 for the same substrates with the $C$. perfringens neuraminidase, as assayed by the periodic acidthiobarbituric acid (PTA) assay method (Skoza \& Mohos, 1976).

Assays of neuraminidase sensitivity of the sialic acid from $A$. viscosus cells were performed at least three times with 0.1 unit of enzyme from $C$. perfringens, Ar. ureafaciens or $V$. cholerae, or with $15 \mu \mathrm{g}$ (total protein) of the $A$. viscosus enzyme. The reaction mixture contained $200 \mu \mathrm{l}$ of $\mathrm{T} 14 \mathrm{~V}$ or T14AV harvested in early exponential phase, washed three times in PBS and suspended in buffer to $200 \mathrm{Klett}$ units. All neuraminidase assays were performed in PBS at pH 7 (Costello et al., 1979) for 1 and $24 \mathrm{~h}$ at $37^{\circ} \mathrm{C}$, except for $V$. cholerae neuraminidase which was assayed in $0 \cdot 1 \mathrm{M}$-sodium acetate $/ 1 \mathrm{mM}-\mathrm{CaCl}_{2} / 0 \cdot 15 \mathrm{M}-\mathrm{NaCl}, \mathrm{pH} 7 \cdot 0$. The low $\mathrm{pH}(4 \cdot 5)$ routinely used for neuraminidase assays resulted in release of sialic acid from $A$. viscosus controls without added enzyme. At the end of the incubation period, the cells were sedimented and the supernatant fluids were assayed for released sialic acid by the PTA method. Enzyme activity was routinely assayed with $100 \mu \mathrm{g} \mathrm{BSM}$ as a control substrate. Controls consisted of bacterial cells incubated in the appropriate buffer.

Colorimetric assays. The PTA assay of Skoza \& Mohos (1976) was used, and the absorption spectrum from 500 to $600 \mathrm{~nm}$ was determined on a Beckman model 25 spectrophotometer.

The direct Ehrlich's reaction of Werner \& Odin (1952) was scaled down to one-tenth of the original volumes. The absorption spectrum from 500 to $600 \mathrm{~nm}$ was used to confirm the presence of sialic acid.

The resorcinol method of Svennerholm (1957) was performed with $1 \mathrm{ml}$ of aqueous sample, and the absorption spectrum of the extract was determined from 550 to $650 \mathrm{~nm}$.

Values calculated from the standard curves of colorimetric assays were determined by linear regression analysis of duplicates.

Paper chromatography. Acid hydrolysates of A. viscosus strain T14V harvested at late exponential phase $(20 \mathrm{~h})$ from two individual cultures were examined by paper chromatography in two different solvent systems. Descending paper chromatography was performed on Whatman no. 1 paper with ethyl acetate/pyridine/water $(60: 25: 20$, by vol.) for $4 \mathrm{~h}$ (system 1) (Baker \& Kasper, 1976a), or with 1-butanol/1-propanol/0 $1 \mathrm{M}-\mathrm{HCl}(1: 2: 1$, by vol.) for $16 \mathrm{~h}$ (system 2) (Svennerholm \& Svennerholm, 1958). Chromatograms were stained with alkaline silver nitrate (Trevelyan et al., 1950) or with resorcinol (Svennerholm \& Svennerholm, 1958). Authentic NeuAc was used as a standard, $5 \mu \mathrm{g}$ for silver nitrate staining and $10 \mu \mathrm{g}$ for resorcinol staining. Acid hydrolysates, containing comparable amounts of sialic acid (as determined by the PTA method) were utilized for analyses.

Epifuorescence detection of lectin binding. For direct FITC-LPA binding, cultures were harvested at $16 \mathrm{~h}$ by centrifugation, washed twice with PBS, $\mathrm{pH} 7 \cdot 2$, washed once with LPA buffer $(0.05 \mathrm{M}-\mathrm{Tris} / \mathrm{HCl}, \mathrm{pH} 7.8,0.01 \mathrm{M}-$ $\mathrm{CaCl}_{2}, 0 \cdot 15 \mathrm{M}-\mathrm{NaCl}$ ), and suspended to $250 \mathrm{Klett}$ units. The conjugated lectin, as supplied, binds as large irregular masses of fluorescent material. More uniform FITC-LPA binding to A. viscosus T14V was obtained by prior dissociation of the aggregated lectin by addition of EDTA $(0.01 \mathrm{M}$ final concentration). Buffer $(1.0 \mathrm{ml})$ containing $100 \mu \mathrm{g}$ FITC-LPA was added to $200 \mu \mathrm{l}$ bacterial suspension. The lectin binding reaction was initiated by restoration of $\mathrm{Ca}^{2+}$ to $10 \mathrm{mM}$. After incubation at $37^{\circ} \mathrm{C}$ for $15 \mathrm{~min}$, glutaraldehyde was added to $1 \cdot 25 \%(\mathrm{v} / \mathrm{v}$ ) final concentration. The bacteria were centrifuged immediately for $3 \mathrm{~min}$ at $11200 \mathrm{~g}$ in a Beckman Microfuge 11 and then washed three times in LPA buffer to remove unbound FITC-LPA and glutaraldehyde. Glutaraldehyde fixation contributed low background fluorescence to the bacterial cells, but this was not sufficiently bright to expose photographic film under the conditions utilized. Sedimented bacteria were suspended in $200 \mu$ LPA buffer and examined by phase-contrast and epifluorescence microscopy. Representative fields were photographed on 
Kodak Panatomic X and/or Kodak Kodachrome II film. Group B type IIJ Streptococcus was utilized as the positive control for FITC-LPA binding, and an oral isolate of Streptococcus faecalis as the negative control.

An indirect method was also employed to demonstrate lectin binding. Washed bacterial cells were treated with $100 \mu \mathrm{g} \mathrm{LPA}$ as described above. After fixation with glutaraldehyde and three washes in buffer, the bacterial pellet was suspended in $200 \mu \mathrm{l}$ LPA buffer, $\mathrm{pH} 7.4$, and incubated at $37^{\circ} \mathrm{C}$ for $1 \mathrm{~h}$ in the presence of $0.5 \mathrm{ml} \mathrm{FITC}$ labelled rabbit anti-LPA $\left(0.9 \mathrm{mg} \mathrm{ml}^{-1}\right)$. The treated cells were washed three times with LPA buffer and examined by phase-contrast and epifluorescence microscopy as above.

Competitive inhibition studies were performed as described above except that solid NeuAc was added to the reaction mixture to $0 \cdot 1 \mathrm{M}$ final concentration.

All epifluorescence experiments were repeated on at least three occasions.

Lectin agglutination. Cultures of $A$. viscosus strains T14V and T14AV were harvested and washed as described above. Cell suspensions were prepared in appropriate buffers to $60 \mathrm{Klett}$ units. The lectins tested for interactions were LPA, which binds sialic acid, LFA, which also recognizes sialic acid, and WGA, which interacts with both sialic acid and $N$-acetylglucosamine- $\beta$-1,4- $N$-acetylglucosamine. LPA and LFA were used with LPA buffer and WGA was examined in PBS. Autoaggregates were dispersed by brief sonication $(5 \mathrm{~s})$ prior to the assay. Each reaction mixture consisted of $0.1 \mathrm{ml}$ bacterial suspension plus $0.1 \mathrm{ml}$ lectin solution containing 10,15 or $100 \mu \mathrm{g}$ lectin. The suspensions were placed into O-ring plates and agitated on a rotary platform at 120 r.p.m. for $10 \mathrm{~min}$ at room temperature. Agglutination was scored with lectin-treated suspensions compared to controls without added lectin. The extent of agglutination was scored from 0 to $4+$ relative to the agglutination of the group B type III Streptococcus control. Agglutination of the latter with $5 \mu \mathrm{g} \mathrm{LPA}$ was assigned a value of $1+$. Inhibition of lectin interactions was performed by the addition of solid NeuAc (final concentration, $0 \cdot 1 \mathrm{M}$ ) to the bacterial suspensions prior to the addition of lectin. Other A. viscosus strains were tested with $25 \mu \mathrm{g} \mathrm{LPA}$ as described for strains T14V and T14AV. Agglutination reactions were reproducible from at least three cultures of each strain.

\section{RESULTS}

Release of sialic acid from A. viscosus. In order to determine the optimal condition for this system, sialic acid release from $A$. viscosus strains T14V and T14AV was measured by the PTA method under various conditions of mild acid hydrolysis as outlined in Methods. Strong mineral acids and high temperatures, usually employed for sialoglycoprotein and glycolipid hydrolyses $\left(0 \cdot 1 \mathrm{M}, 1-2 \mathrm{~h}, 80-85^{\circ} \mathrm{C}\right)$, yielded no sialic acid from $A$. viscosus cells. Reduction of mineral acid concentration to $0.01 \mathrm{M}$ and of temperature to 0 or $37^{\circ} \mathrm{C}$ improved recovery from strain $\mathrm{T} 14 \mathrm{~V}$, but not from strain T14AV. Approximately the same amount of sialic acid was recovered from strain $\mathrm{T} 14 \mathrm{~V}$ by extraction in both distilled water and in $0.35 \mathrm{M}$-acetic acid for $60 \mathrm{~min}$ at $37^{\circ} \mathrm{C}$. Only the latter condition was appropriate for recovery of sialic acid from strain T14AV.

Release of sialic acid from $A$. viscosus by commercial neuraminidase preparations was unsuccessful. Washed early exponential phase cells of strains $\mathrm{T} 14 \mathrm{~V}$ and $\mathrm{T} 14 \mathrm{AV}$ were incubated for 1 and $24 \mathrm{~h}$ at $37^{\circ} \mathrm{C}$ with $0 \cdot 1$ unit of neuraminidase from $C$. perfringens, Ar. ureafaciens or $V$. cholerae. The sialic acid content of the enzyme reaction supernatant fluids and control values of bacteria incubated in buffer alone were below the limit of detection for the PTA assay $(0.01 \mu \mathrm{g})$. However, the crude preparation of the neuraminidase from $A$. viscosus $\mathrm{T} 14 \mathrm{~V}$ did cleave sialic acid from whole organisms. The amount of sialic acid released was equivalent to that obtained by acid hydrolysis.

Colorimetric assays. Fig. 1 shows the absorption spectra of authentic $\mathrm{N}$-acetylneuraminic acid and the mild acid hydrolysate of $A$. viscosus T14V produced by the PTA assay, the direct Ehrlich's reaction and the resorcinol method. The profiles of the bacterial hydrolysate and the standard are comparable in all three tests, and indicate a spectrum of reactivity consistent with the presence of sialic acid in $A$. viscosus strain $\mathrm{T} 14 \mathrm{~V}$. Similar results were obtained for strain T14AV (data not shown).

Paper chromatography. In order to confirm the results obtained by colorimetric derivatization, paper chromatographic separation was utilized. The mild acid hydrolysate of $A$. viscosus strain T14V harvested at late exponential phase $(20 \mathrm{~h})$ showed co-chromatography with authentic NeuAc in both system $1\left(R_{F}=0.245\right)$ and system $2\left(R_{F}=0.478\right)$. System 1 revealed an array of compounds which might obscure NeuAc or give a false positive; system 2 separated NeuAc well away from contaminating compounds. Visualization of the chromatogram obtained from 


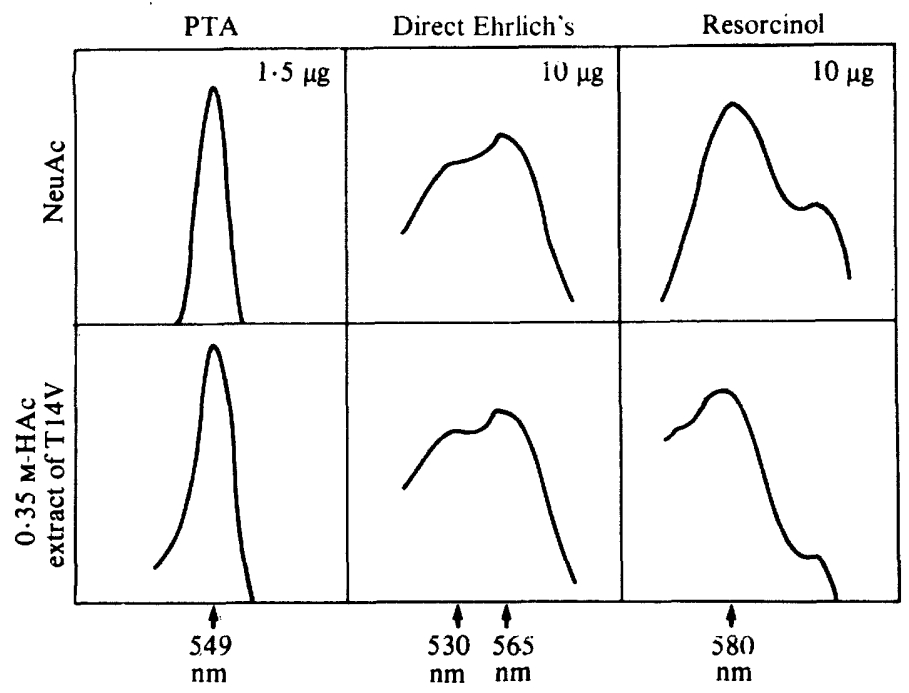

Fig. 1. Comparison of absorption spectra obtained for $N$-acetylneuraminic acid (NeuAc) and the hydrolysate from $A$. viscosus $\mathrm{T} 14 \mathrm{~V}$ in the PTA, direct Ehrlich's and resorcinol assays. In the top row, the amount of authentic NeuAc is indicated in the upper right corner of each panel. The bottom row shows the spectra produced from $A$. viscosus strain T14V harvested at $20 \mathrm{~h}$ and hydrolysed in $0.35 \mathrm{M}$-acetic acid (HAc) for $45 \mathrm{~min}$ at $37^{\circ} \mathrm{C}$. The top line of each panel represents 0.25 absorbance units. Arrows at the bottom of the figure indicate the absorbance maxima for the sialic acid product of each colour reaction.

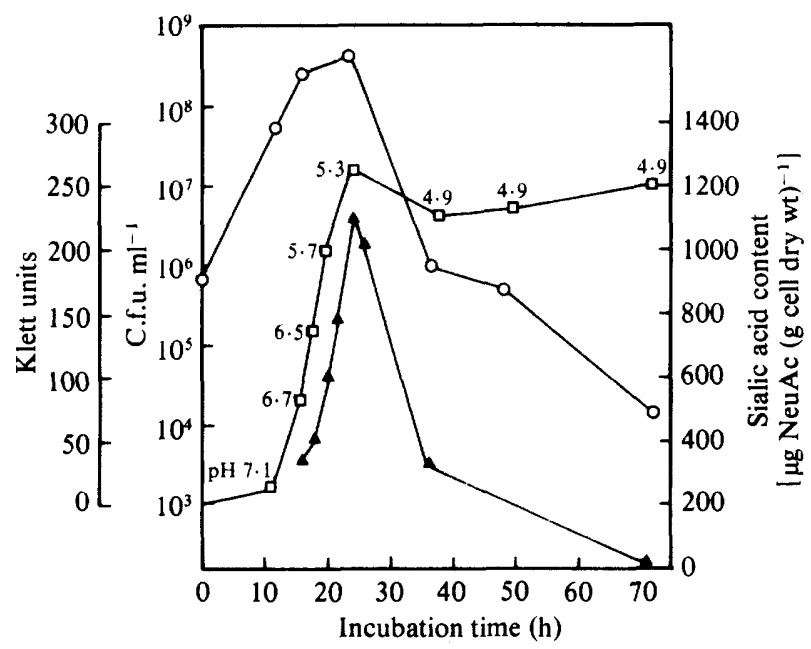

Fig. 2. Sialic acid contents of $A$. viscosus $\mathrm{T} 14 \mathrm{~V}$ in batch culture as a function of incubation time. $\Delta$, Sialic acid content; $O$, cell viability; $\square$, cell density. The $\mathrm{pH}$ of the culture at each time point is indicated on the graph. Cells were hydrolysed in $0.35 \mathrm{M}$-acetic acid for $45 \mathrm{~min}$ at $37^{\circ} \mathrm{C}$, and the sialic acid released was determined by the PTA method. All values represent means obtained from nine separate experiments.

system 2 with resorcinol confirmed that the spot which co-migrated with authentic NeuAc reacted to give the same violet-coloured derivative.

Production of sialic acid in batch culture. The sialic acid content of $A$. viscosus strain T14V was examined as a function of stage of growth (Fig. 2). The amount of sialic acid per $\mathrm{g}$ dry weight of cells increased threefold during the exponential phase of growth to a maximum during early stationary phase. Sialic acid content thereafter decreased in concert with the decrease in cell 

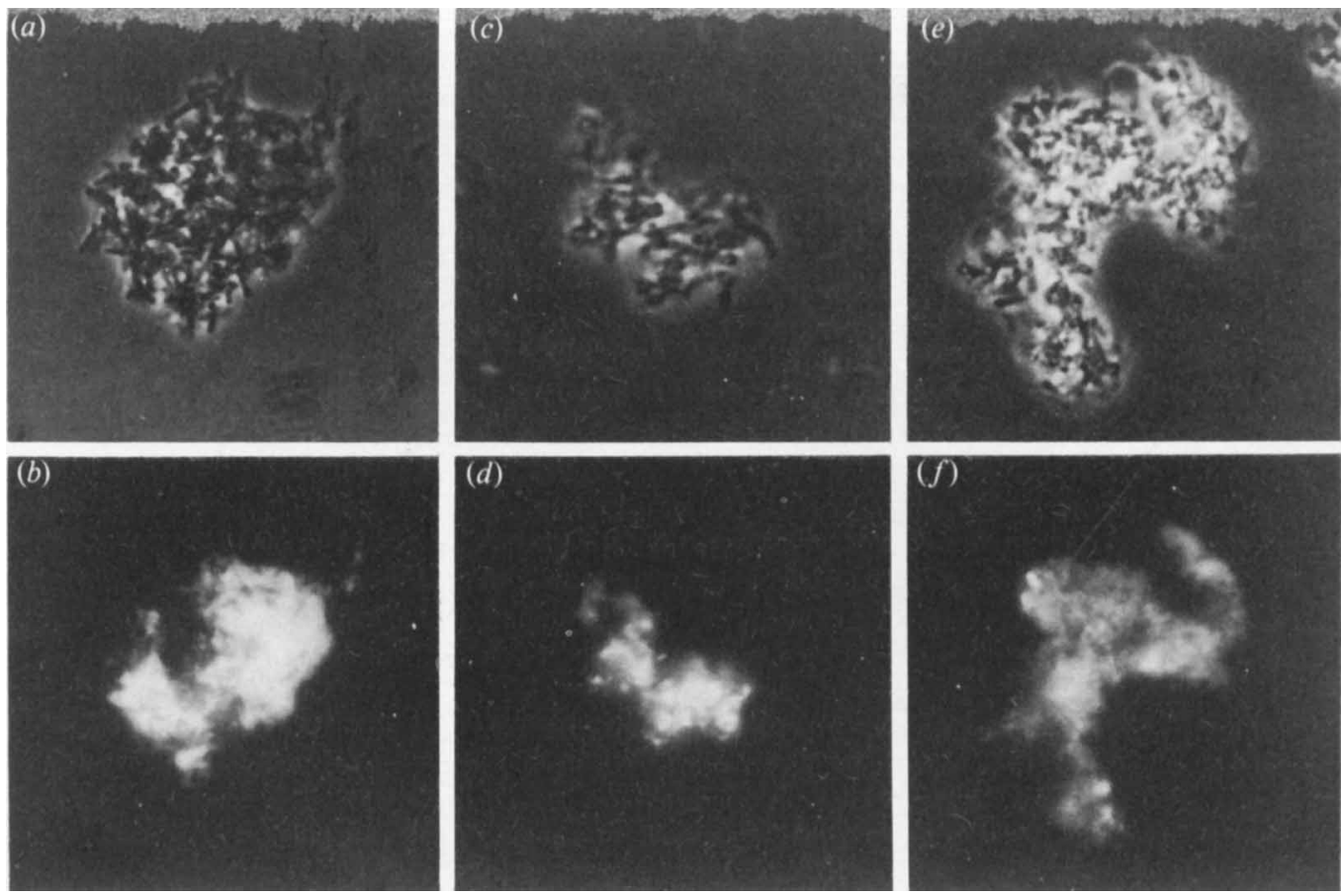

Fig. 3. Phase-contrast $(a, c, e)$ and epifluorescence $(b, d, f)$ photomicrographs of $A$. viscosus cells reacted with LPA. Direct staining with FITC-LPA is shown for strains T14V $(a, b)$ and T14AV $(c, d)$. Strain $\mathrm{T} 14 \mathrm{~V}$ was also reacted with LPA followed by FITC-conjugated rabbit anti-LPA $(e, f)$. Magnification approx. $\times 1600$.

viability. The maximum content of sialic acid in strain $\mathrm{T} 14 \mathrm{~V}$ was $0.1 \%$ of the dry weight. Dry weights varied from $148 \mathrm{mg}$ per $\mathrm{g}$ wet weight in the early exponential phase to $184 \mathrm{mg}$ per $\mathrm{g}$ wet weight in the early stationary phase.

Epiftuorescence microscopy. Surface localization of sialic acid on $A$. viscosus strains T14V and T14AV was visualized by the use of FITC-conjugated LPA, a lectin specific for glycosidic sialic acid, and by an indirect method with FITC-labelled rabbit anti-LPA. Lectin-agglutinated cells of both strain T14V (Fig. 3a,b) and strain T14AV (Fig. 3c,d) displayed a uniform distribution of bright green fluorescence.

Chemical modification of a lectin to produce a fluorescent derivative could possibly alter its binding specificity. To confirm that the specific lectin-carbohydrate interaction had occurred, unmodified LPA was incubated with a cell suspension of strain $\mathrm{T} 14 \mathrm{~V}$, and then stained with FITC-conjugated rabbit antiserum to LPA. Comparable results were obtained (Fig. $3 e, f$ ), demonstrating that both the lectin and its conjugate bind a cell surface component. Both LPA and FITC-LPA binding were inhibited by $0.1 \mathrm{M}-\mathrm{NeuAc}$. Fluorescence of T14V and T14AV was greatly reduced by incorporation of the competing sugar into the reaction mixture.

Lectin agglutination. Surface localization of sialic acid in $A$. viscosus strains was further supported by bacterial cell agglutination with specific lectins. Strains T14V and T14AV were tested with affinity-purified lectins reported to bind sialic acid residues. Agglutination of strain T14V could be achieved with as little as $1 \mu \mathrm{g}$ LPA. Maximum agglutination $(4+)$ occurred over a range of $50-100 \mu \mathrm{g}$ lectin under the assay conditions employed, but ordinarily was evaluated at $25 \mu \mathrm{g}(3+)$. Agglutination of strain T14AV with LPA was less by one unit than that obtained with strain $\mathrm{T} 14 \mathrm{~V}$ at the same lectin concentrations (see Table 1). LPA-mediated aggregation of both strains was inhibited by $0 \cdot 1 \mathrm{M}-\mathrm{NeuAc}$. Late stationary phase cells, which possessed no sialic acid, did not agglutinate with LPA. 
Table 1. Content of sialic acid in A. viscosus strains

Colour assays and lectin agglutinations were performed on three individual $20 \mathrm{~h}$ cultures grown on separate occasions. Standard deviations were calculated from the mean of duplicate values obtained from each hydrolysate of the three individual cultures.

\begin{tabular}{|c|c|c|c|}
\hline \multirow[b]{2}{*}{$\begin{array}{l}\text { Strain of } \\
\text { A. viscosus }\end{array}$} & \multicolumn{3}{|c|}{ Sialic acid content as determined by: } \\
\hline & \multicolumn{2}{|c|}{$\begin{array}{cc}\text { PTA } & \text { Direct } \\
{\left[\mu \mathrm{g} \text { NeuAc }(\mathrm{g} \text { wet } w t)^{-1} \pm \mathrm{SD}\right]}\end{array}$} & \multirow{2}{*}{$\begin{array}{l}\text { Lectin (LPA) } \\
\text { agglutination } \\
+++\end{array}$} \\
\hline $14 \mathrm{~V}$ & $192 \pm 26$ & $215 \pm 17$ & \\
\hline $14 \mathrm{AV}$ & $16 \pm 1$ & $23 \pm 4$ & ++ \\
\hline 1053 & $323 \pm 7$ & $323 \pm 21$ & ++ \\
\hline 859 & $61 \pm 3$ & $40 \pm 15$ & + \\
\hline 100 & $22 \pm 2$ & $32 \pm 1$ & $+t+$ \\
\hline $5 S$ & $46 \pm 12$ & $27 \pm 6$ & + \\
\hline $\mathrm{C} 45$ & $30 \pm 10$ & $25 \pm 2$ & + \\
\hline АТCC 19246 & $62 \pm 20$ & $58 \pm 26$ & + \\
\hline Binder' & $31 \pm 19$ & $23 \pm 5$ & + \\
\hline B3 & $67 \pm 4$ & $72 \pm 4$ & ++ \\
\hline SB4 & $63 \pm 3$ & $64 \pm 1$ & + \\
\hline $\mathrm{F} 620$ & $14 \pm 4$ & $11 \pm 1$ & $+t+t$ \\
\hline F633 & $13 \pm 3$ & $12 \pm 2$ & $++t+$ \\
\hline JF810 & $27 \pm 2$ & $24 \pm 2$ & ++ \\
\hline Group B type & & & \\
\hline Streptococcus & 1200 & 720 & $+^{*}$ \\
\hline
\end{tabular}

* Agglutination with group B type III Streptococcus was determined at $5 \mu \mathrm{g}$ instead of $25 \mu \mathrm{g}$ LPA.

Agglutination of $A$. viscosus T14A and T14AV with other sialic acid lectins was not comparable to that achieved with LPA. The sialic-acid-specific lectin LFA agglutinated cells of strain T14V weakly, was inhibited by $0.1 \mathrm{M}-\mathrm{NeuAc}$, and did not react with T14AV. WGA has been reported to interact with sialic acid (Bhavanandan \& Katlic, 1979), but did not aggregate A. viscosus strains $\mathrm{T} 14 \mathrm{~V}$ and $\mathrm{T} 14 \mathrm{AV}$.

Other strains of $A$. viscosus. Each strain was harvested in late exponential phase $(20 \mathrm{~h})$, tested for whole-cell agglutination with LPA, and assayed by the PTA and direct Ehrlich's methods. All laboratory strains and clinical isolates were positive for sialic acid by the three criteria tested (Table 1). The large standard deviations reported in Table 1 probably reflect the great variation in sialic acid content as a function of stage of growth. This is consistent with our observations with strain $\mathrm{T} 14 \mathrm{~V}$, where small differences in the time of cell harvest result in large differences in sialic acid content (see Fig. 2).

\section{DISCUSSION}

The establishment of appropriate hydrolysis conditions for quantitative release of sialic acid from $A$. viscosus was essential for chemical demonstration, but was hampered by the acid lability of the compound. Use of the conventional techniques for glycoproteins and glycolipids (Schauer, 1982) with $A$. viscosus produced little or no detectable sialic acid from T14V and none from T14AV. Substitution of acetic acid for strong mineral acids and reduction of temperature achieved adequate recovery from this organism. Acetic acid hydrolysis minimizes destruction of sialic acids (Varki \& Diaz, 1984).

Bacterial sialic acid residues are often resistant to the action of neuraminidases due to $O$ acetylation or intrachain lactone formation (Liu et al., 1971; McGuire \& Binkley, 1964; Shigeoka et al., 1983). The commercial enzymes utilized in this study collectively cleave $\alpha-2,3$, $\alpha-2,6$ and $\alpha-2,8$ ketosides on glycoprotein, glycolipid and oligosaccharide substrates, including colominic acid (Corfield et al., 1981). Each enzyme varies in activity towards specific glycosidic 
linkages and is influenced by adjacent glycose units as well as the extent of sialic acid derivatization. These considerations limit any structural conclusions which might be made as to the exact nature of the residue and its chemical environment.

A. viscosus $\mathrm{T} 14 \mathrm{~V}$ has been described as possessing both a cell-associated and an extracellular form of neuraminidase (Costello et al., 1979). Both the cell-bound and soluble enzymes were active with glycoproteins in solution, but only the extracellular form cleaved surface sialic acid from human erythrocytes. The same pattern of activity was observed when $A$. viscosus T14V was used as the neuraminidase substrate. Although both the soluble neuraminidase and bacterial cell suspensions released sialic acid from BSM, control reactions of $A$. viscosus cells yielded no free sialic acid. Addition of the extracellular neuraminidase to a suspension of mid-exponential phase cells did release sialic acid.

Sialic acids may be assayed by several methods which vary in specificity, sensitivity and appropriateness for use with complex samples. No one colorimetric assay is sufficiently specific to demonstrate the presence of sialic acid unequivocally. Those selected in this study were chosen on the basis of adequate sensitivity for the material tested and mutual elimination of potential cross-reacting substances (Schauer, 1982). The most sensitive and specific method in common use is the PTA assay, which requires non-glycosidic sialic acid as a substrate. The most common interference is from the deoxyribose chromophore $\left(\lambda_{\max } 532 \mathrm{~nm}\right)$ which can obscure the sialic acid peak $\left(\lambda_{\max } 549 \mathrm{~nm}\right)$. The only group of compounds which produce the same chromophore as sialic acids are 3-deoxyaldulosonic acids, such as 3-deoxyoctulosonic acid (KDO) (Kuwahara, 1980). The position of the $\lambda_{\max }$ in absorption spectra from 500 to $600 \mathrm{~nm}$ can be used to determine the relative contributions of the 2-deoxyribose and sialic acid chromogens. The direct Ehrlich's reaction is characteristic of sialic acids and does not require prior hydrolysis, but it is comparatively insensitive and forms interfering chromophores from hexosamines, neutral sugars and lysine. The resorcinol method also may be performed on unhydrolysed material and is more sensitive than the Ehrlich's reaction, but serious interference from proteins, pentoses and hexoses can occur (Schauer, 1982; Werner \& Odin, 1952). The sialic acid chromophore of the Ehrlich's reaction has two absorption maxima, 565 and $530 \mathrm{~nm}$; the resorcinol product has a maximum at $580 \mathrm{~nm}$. Analysis of these colour reactions by absorption spectra was also used to evaluate colour contributions of possible interfering compounds. Neither the direct Ehrlich's nor resorcinol methods are subject to interference by 3deoxyaldulosonic acids, the only potential cross-reactants in the PTA assay. The combination of characteristic colour reactions and co-chromatography on paper with NeuAc support the conclusion that sialic acid occurs on $A$. viscosus.

The variation of sialic acid content with stage of growth in batch culture is similar to that observed for group B type III streptococci (Baker \& Kasper, 1976 b; Jennings et al., 1980). Sialic acid content increases through exponential growth, reaches a maximum in early stationary phase, and is affected by the $\mathrm{pH}$ of the culture medium. Not only does the amount of cellassociated sialic acid rise during the exponential phase of growth, but the hydrolysable sialic acid content of the culture supernatant fluid also increases. This probably occurs as a result of shedding, and not the extracellular neuraminidase, as free sialic acid was not detected in culture supernatant fluid (unpublished observations).

The LPA lectin for sialic acid shows the greatest specificity towards glycoproteins with NeuAc in $\alpha-2,3$ or $\alpha-2,6$ linkage to $N$-acetylgalactosamine. $N$-Acetylhexosamines show no activity with the lectin (Roche \& Monsigny, 1978). LPA also recognizes glucuronides (Vaith et al., 1978), gangliosidic $N$-glycolylneuraminic acid (Maget-Dana et al., 1978) and LPS-associated KDO (Rostam-Abadi \& Pistole, 1982). The binding of LPA to A. viscosus strain T14V could be inhibited by addition of NeuAc to $0.1 \mathrm{M}$, even in the presence of glutaraldehyde. This observation argues against nonspecific lectin binding as a consequence of fixation. Furthermore, the chemical tests performed exclude glucuronate and KDO as potential candidates for the site of lectin binding. Both solvent systems utilized for paper chromatography can resolve $N$-glycolylneuraminic acid from the $N$-acetyl derivative; therefore, the $N$-glycolyl form is also unlikely to be the ligand. Bacterial cell agglutination with LPA in the absence of glutaraldehyde supports the specific nature of the lectin interaction. The sialic acid lectin LFA, 
which recognizes both $N$-acetyl- and $N$-glycolylneuraminic acids (Miller et al., 1981), does not react as strongly as LPA with $A$. viscosus, but the results with this lectin may be interpreted as corroborating the data obtained with LPA. WGA binds to the type-specific polysaccharides of the group B streptococci (Gray et al., 1984), but it did not agglutinate $A$. viscosus.

In order to determine whether surface sialic acid is a widespread trait of $A$. viscosus serotype 2 strains, or whether it is restricted to the strains $\mathrm{T} 14 \mathrm{~V}$ and $\mathrm{T} 14 \mathrm{AV}$, several laboratory strains and clinical isolates were tested for the presence of this compound. The lectin agglutination assay was selected as the method for demonstrating surface localization among the strains tested. The PTA and the direct Ehrlich's assays were chosen on the basis of sensitivity and overlapping specificity, as the only compound which gives a positive reaction in both tests is sialic acid. There was no correlation between the extent of lectin agglutination and sialic acid content. This could reflect the availability of terminal sialic acid residues for binding, steric hindrance, or the influence of adjacent residues. The values obtained by the two colorimetric methods were not always in agreement, due either to the presence of cross-reacting compounds released by acid hydrolysis or to the variable PTA absorption coefficients obtained for different sialic acid derivatives. Even in the case of the group B type III Streptococcus, sialic acid contents estimated by the PTA and direct Ehrlich's methods were not equivalent.

The potential significance of surface-available sialic acid in $A$. viscosus remains to be evaluated. However, a consideration of some aspects of pathogenesis of sialidated $E$. coli strains and group B type III Streptococcus indicates that the primary effects are to inhibit alternative complement pathway activation and thereby thwart subsequent opsonophagocytosis and to enhance invasiveness (Bortolussi et al., 1979: Fearon, 1978). Sialidated E. coli strains do not produce capsular material when grown below $30^{\circ} \mathrm{C}$ and are readily opsonized. Cells grown at $37^{\circ} \mathrm{C}$ produce sialic acid and are not opsonized (Bortolussi et al., 1983). No serotype of the group B type III streptococci examined activates the alternative complement pathway to any significant extent, and that activation can occur only when specific antibody titres toward the capsule are quite high (Edwards et al., 1980). Enzymic and chemical modification of capsular sialic acid in type III Streptococcus results in a marked increase in consumption of complement factor C3 (Edwards et al., 1982). These findings are consistent with the hypothesis that the amount of surface-available sialic acid may regulate the initiation of activation of the alternative complement pathway (Fearon, 1978; Kazatchkine et al., 1979; Pangburn \& Muller-Eberhard, 1978). Enhanced invasiveness appears to be conferred by the sialic acid heteropolymer of group B type III streptococci. Mutants deficient in either production or cell wall linkage of the typespecific polysaccharide are cleared rapidly when injected into mice, whereas the wild-type strain disseminates quickly to other tissues (Yeung \& Mattingly, 1983, 1984). The sialidated capsular material of $E$. coli strains associated with neonatal meningitis is antigenically and biochemically identical (except for polymer length) to a cell surface sialic acid homopolymer that occurs on neuronal cells of chick embryos and newborn rats (Vimr et al., 1984). Antisera to group B meningococci cross-react with isolated polysialosyl glycopeptides from both human and rat foetal brain tissues (Finne et al., 1983). These findings suggest that host antigen mimicry may be an additional virulence factor for these micro-organisms.

The occurrence of sialic acid on a numerically important member of the normal oral flora may have certain implications for its ability to colonize and to evade the host defence mechanisms available in the gingival crevice. It has been reported that certain strains of Streptococci sanguis are agglutinated with saliva and serum components in a sialic-acid-dependent fashion (Levine $e t$ al., 1978; Morris \& McBride, 1983). S. sanguis strain KS32AR possesses a lectin specific for NeuAc in a trisaccharide sequence consistent with the carbohydrate composition of a purified salivary mucin (Murray et al., 1982). These observations suggest that sialic-acid-containing polymers are an important determinant in the establishment and maintenance of the normal oral flora. Studies to demonstrate the significance of sialic acid on $A$. viscosus would require careful attention to the physiological state of the organism and its surface content of sialic acid. 


\section{REFERENCES}

Apicella, M. A. \& Robinson, J. B. (1970). Physicochemical properties of Neisseria meningitidis group C and $\mathrm{Y}$ polysaccharide antigens. Infection and Immunity 2, 392-397.

BAKER, C. J. \& KASPER, D. L. (1976a). Identification of sialic acid in polysaccharide antigens of group B Streptococcus. Infection and Immunity 13, 284-288.

BAKER, C. J. \& KASPER, D. L. (1976b). Microcapsule of type III strains of group B Streptococcus: production and morphology. Infection and Immunity 13, 189-194.

BARRY, G. T. (1959). Detection of sialic acid in various Escherichia coli strains and in other species of bacteria. Nature, London 183, $117-118$.

Barry, G. T., AbBotT, V. \& Tsai, T. (1962). Relationship of colominic acid (poly $\mathrm{N}$-acetylneuraminic acid) to bacteria which contain neuraminic acid. Journal of General Microbiology 29, 335-352.

Bhavanandan, V. P. \& Katlic, A. W. (1979). The interaction of wheat germ agglutinin with sialoglycoproteins. Journal of Biological Chemistry 254, 40004008.

Bortolussi, R., Ferrieri, P., Bjorksten, B. \& Quie, P. G. (1979). Capsular K I polysaccharide of Escherichia coli: relationship to virulence in newborn rats and resistance to phagocytosis. Infection and Immunity 25, 293-298.

Bortolussi, R., Ferrieri, P. \& Quie, P. G. (1983). Influence of growth temperature of Escherichia coli on $\mathrm{Kl}$ capsular antigen production and resistance to opsonization. Infection and Immunity 39, 1136-1141.

Brecher, S. M., Van Houte, J. \& Hammond, B. F. (1978). Role of colonization in the virulence of Actinomyces viscosus strains $\mathrm{T} 14-\mathrm{Vi}$ and $\mathrm{T} 14-\mathrm{Av}$. Infection and Immunity 22, 603-614.

CORfield, A. P., Michalski, J.-C. \& Schauer, R. (1981). The substrate specificity of sialidases from microorganisms and mammals. Perspectives in Inherited Metabolic Diseases 4, 3-70.

Costello, A. H., Cisar, J. O., Kolenbrander, P. E. \& GABRIEL, O. (1979). Neuraminidase-dependent hemagglutination of human erythrocytes by human strains of Actinomyces viscosus and Actinomyces naeslundii. Infection and Immunity 26, 563-572.

Dawes, J., Tuach, S. J. \& McBride, W. H. (1974). Properties of an antigenic polysaccharide from Corynebacterium parvum. Journal of Bacteriology 120 , 24-30.

EdWards, M. S., Nicholson-Weller, A., BaKer, C. J. \& Kaspar, D. L. (1980). The role of specific antibody in alternative complement pathway-mediated opsonophagocytosis of type III, group B Streptococcus. Journal of Experimental Medicine 151, 1275-1287.

Edwards, M. S., Kasper, D. L., Jennings, H. J., BAKER, C. J. \& Nicholson-WelleR, A. (1982). Capsular sialic acid prevents activation of the alternative complement pathway by type III, group B streptococci. Journal of Immunology 128, 12781283.

FEARON, D. T. (1978). Regulation by membrane sialic acid of $\beta 1 \mathrm{H}$-dependent decay-dissociation of amplification $\mathrm{C} 3$ convertase of the alternative complement pathway. Proceedings of the National Academy of Sciences of the United States of America 75, 1971 1975.
Finne, J., Leinonen, M. \& MÄKelä, P. H. (1983). Antigenic similarities between brain components and bacteria causing meningitis. Lancet 2, 355-357.

Gray, B. M., Dillon, H. C. \& Pritchard, D. G (1984). Interaction of group B streptococcal typespecific polysaccharides with wheat germ agglutinin and other lectins. Journal of Immunological Methods 72, 269-277.

Jennings, H. J., Rosell, K.-G. \& Kaspar, D. L. (1980). Structure and serology of the native polysaccharide antigen of type Ia group B Streptococcus. Proceedings of the National Academy of Sciences of the United States of America 77, 2931-2935.

Jones, A. H., Marroquin, R. \& Birdsell, D. C. (1983). Sialic acid in Actinomyces viscosus strains T14V and T14AV. (Abstract) Journal of Dental Research 62A, 657.

Jordan, H. V., Keyes, P. H. \& Bellack, S. (1972). Periodontal lesions in hamsters and gnotobiotic rats infected with actinomyces of human origin. Journal of Periodontal Research 7, 21-28.

KaZatchrine, M. D., Fearon, D. T. \& Austen, K. F (1979). Human alternative complement pathway: membrane-associated sialic acid regulates the competition between $\mathrm{B}$ and $\beta \mathrm{L} \mathrm{H}$ for cell-bound $\mathrm{C} 3 \mathrm{~b}$. Journal of Immunology 122, 75-81.

KEDZIERSKA, B. (1978). N-Acetylneuraminic acid: a constituent of the lipopolysaccharide of Salmonella toucra. European Journal of Biochemistry 91, 545-552.

KuWAHARA, S. S. (1980). Carbohydrate interference in assays based on the periodate-coupled thiobarbituric acid reagent. Analytical Biochemistry 101, 54-60.

Levine, M. J., Herzberg, M. C., Levine, M. S., Ellison, S. A., Stinson, M. W., Li, H. C. \& Van DYKE, T. (1978). Specificity of salivary-bacterial interactions: role of terminal sialic acid residues in the interaction of salivary glycoproteins with Streptococcus sanguis and Streptococcus mutans. Infection and Immunity 19, 107-115.

LiU, T.-Y., Gotschlich, E. C., Denne, F. T. \& JoNSSEN, E. K. (1971). Studies on the meningococcal polysaccharides. II. Composition and chemical properties of the group $B$ and group $C$ polysaccharide. Journal of Biological Chemistry 246, 4703-4712.

LOESCHE, W. J. \& SYED, S. A. (1978). Bacteriology of human experimental gingivitis: effect of plaque and gingivitis score. Infection and Immunity 21, 830-839.

Maget-Dana, R., Roche, A.-C. \& Monsigny, M. (1978). Ganglioside-limulin interactions. Progress in Clinical and Biological Research 29, 567-578.

McGuire, E. J. \& BinkLeY, S. B. (1964). The structure and chemistry of colominic acid. Biochemistry 3 , 247-251.

Miller, R. L., Fish, W. W. \& Collwan, J. F. (1981). $\mathrm{N}$-Acetylneuraminic acid-specific lectin from slugs. (Abstract) Federation Proceedings 40, 1715.

Moncla, B. J., HalfPap, L. \& Birdsell, D. C. (1985). Langmuir and Scatchard parameters do not describe the binding of Actinomyces viscosus to saliva-treated hydroxyapatite. Journal of General Microbiologv 131. 2619-2626.

MoRRIS, E. J. \& MCBRIDE, B. C. (1983). Aggregation of Streptococcus sanguis by a neuraminidase-sensitive component of serum and crevicular fluid. Infection and Immunity 42, 1073-1080. 
Mulder, C. J. J. \& Zanen, H. C. (1984). Neonatal group B streptococcal meningitis. Archives of Disease in Childhood 59, 439-443.

Murray, P. A., LeVine, M. J., Tabak, L. A. \& Reddy, M. S. (1982). Specificity of salivary-bacterial interactions. II. Evidence for a lectin on Streptococcus sanguis with specificity for a NeuAc $\alpha 2,3 \mathrm{Gal} \beta 1$, 3GalNAc sequence. Biochemical and Biophysical Research Communications 106, 390-396.

Newman, M. G. \& Sims, T. N. (1979). The predominant cultivable microbiota of the periodontal abcess. Journal of Periodontology 50, 350-354.

Pangburn, M. K. \& Muller-Eberhard, H. J. (1978). Complement $\mathrm{C} 3$ convertase: cell surface restriction of $\beta 1 \mathrm{H}$ control and generation of restriction on neuraminidase-treated cells. Proceedings of the $\mathrm{Na}$ tional Academy of Sciences of the United States of America 75, 2416-2420.

Robbins, J. B., McCraken, G. H., Gotschlich, E. C., ØRSKov, F., ØrSKov, I. \& HaNSON, L. A. (1974) Escherichia coli $\mathrm{K} 1$ capsular polysaccharide associated with neonatal meningitis. New England Journal of Medicine 290, 1216-1220.

Roche, A.-C. \& MonsignY, M. (1978). Limulin (Limulus polyphemus lectin). Isolation, physicochemical properties, sugar specificity and mitogenic activity. Progress in Clinical and Biological Research 29, 603-616.

Rostam-Abadi, H. \& Pistole, T. G. (1982). Lipopolysaccharide-binding lectin from the horseshoe crab, Limulus polyphemus, with specificity for 2-keto-3deoxyoctanate (KDO). Developmental and Comparative Immunology 6, 209-218.

Schauer, R. (Editor) (1982). Sialic Acids. New York: Springer-Verlag.

Shigeoka, A. O., Rote, N. S., Santos, J. I. \& Hill, H. R. (1983). Assessment of the virulence factors of group B streptococci: correlation with sialic acid content. Journal of Infectious Diseases 147, 857-863.

SkozA, L. \& MoHos, S. (1976). Stable thiobarbituric acid chromophore with dimethyl sulphoxide. Biochemical Journal 159, 457-462.
SVennerholm, E. \& SVennerholm, L. (1958), Quantitative paper partition chromatography of sialic acids. Nature, London 181, 1154-1155.

SVENNERHOLM, L. (1957). Quantitative estimation of sialic acids. II. A colorimetric resorcinol-hydrochloric acid method. Biochimica et biophysica acta 24 , 604-611.

Syed, S. A. \& Loesche, W. J. (1978). Bacteriology of human experimental gingivitis: effect of plaque age. Infection and Immunity 21, 821-829.

Trevelyan, W. E., Procter, D. P. \& Harrison, J. S. (1950). Detection of sugars on paper chromatograms. Nature, London 166, 444-445.

Vaith, P., Uhlenbruck, G., Muller, W. E. G. \& COHEN, E. (1978). Reactivity of Limulus polyphemus hemolymph with D-glucuronic acid containing glycosubstances. Progress in Clinical and Biological Reseach 29, 579-587.

VARKI, A. \& DIAZ, S. (1984). The release and purification of sialic acids from glycoconjugates: methods to minimize the loss and migration of $O$ acetyl groups. Analytical Biochemistry 137, 236-247.

VIMR, E. R., MCCOY, R. D., Vollger, H. F., WILkISON, N. C. \& TroY, F. A. (1984). Use of prokaryotic-derived probes to identify poly(sialic acid) in neonatal neuronal membranes. Proceedings of the National Academy of Sciences of the United States of America 81, 1971-1975.

WERNER, I. \& ODIN, L. (1952). On the presence of sialic acid in certain glycoproteins and in gangliosides. Acta Societatis medicorum upsalienesis 57, 230-241.

Yeung, M. K. \& Matingly, S. J. (1983). Isolation and characterization of type IIl group B streptococcal mutants defective in biosynthesis of the typespecific antigen. Infection and Immunity 42, 141-151.

YeUNG, M. K \& Matringly, S. J. (1984). Biosynthetic capacity for type-specific antigen synthesis determines the virulence of serotype III strains of group B streptococci. Infection and Inmunity 44, 217-221. 